\title{
The Experience of Students Using MOOC's: Motivation, Attitude, Efficiency
}

\author{
Marina M. Solobutina*1, Natalya N. Kalatskaya ${ }^{2}$ \\ ${ }^{1,2}$ Kazan Federal University, Institute of Psychology and Education, \\ Email: solomarina29@ gmail.com, Contact:+79033424506; kalazkay@mail.ru,Tel.+79053160602.
}

\section{Received: 21st October 2017 Accepted: 16th November 2017, Published: 31st December 2017}

\begin{abstract}
The results of studying the features of students' learning activity, by means of electronic educational resources are presented in the article. 778 students of Kazan (Volga region) Federal University took part in the research. This sample included students from all institutions and fields of education. The sample of the study was divided into two groups. The first group included 399 students, with experience in working with electronic educational resources (EER). The second group consisted of 379 students, who did not have any experience in working with EER. All studied indicators were divided into the following categories: social portrait, learning activity, professional competences, satisfaction with the quality of education, professional development. Questioning and frequency analysis were the methods of the research, used in the work. As a result of the investigation, we obtained significant data. They showed the main distinguishing characteristics of student learning activities, when using electronic educational resources, the specific aspects of educational motivation and the students' attitude to the use of technologies in the educational process.
\end{abstract}

Keywords: Electronic Educational Resources, Learning Activity, Students, Motivation, Professional Competences, Social Portrait.

\section{Introduction}

Higher education in Russia has undergone significant changes in the past decade. And first of all it concerns the methodology of learning. Along with traditional forms of full-time education, more and more spaces in the educational system of universities are occupied by electronic resources, created both on the basis of university courses and on the grounds of open education. In educational researches, the potential of electronic educational resources in appraisal the quality of educational services is of great interest.

Based on the literature reviews, devoted to MOOCs, it is possible to single out various approaches in studying the features of electronic educational resources [8]. The group of researches is devoted to a comparative analysis of the results of traditional learning and education, with the application of electronic courses, as well as the opportunities for combining different forms of learning, their complementarity and interchangeability [2]. These investigations are conducted within the framework of learning theories. It is obvious, that the technological achievements of science affect all spheres of modern world. The possibilities of implementation of technical innovations into the educational process change not only the teachers' instrumental view of the use of various teaching aids, the changes affect the conceptual vision within the theory, methodology and ethics of education $[10,11]$. A lot of researches are devoted to the discussion of specific pedagogical practices, using open online courses [17]. Also, the great interest of researchers is caused by the impact of tendency of education technological development to training of teachers, their professional development and the competence of creation and application of online courses in pedagogical activity [18].

Another approach is connected with studies of the effectiveness of technology implementation in training, with a focus on structuring of electronic courses, content and form of presentation of teaching materials [3]. Patterns of students' behavior are widely studied, when attending online courses, in order to improve the design of courses [14]. In the survey of existing researches of electronic education, Lee \& Choi propose the main modern educational technologies, used in the process of electronic courses creation [7]. In the article of Longstaff, the possibilities of MOOCs in increasing the effectiveness of training are discussed; the goals of course developers with the real experience of training users are compared [9]. Recent researches focus not on the problem of using electronic resources as an alternative to traditional higher learning. The transformation of educational courses takes place within the online educational space: the transition from "traditional" online courses to open education as such [13].

The third approach in the study of electronic educational resources concentrates on the personality of the student. The field of interest of researchers in this area is quite broad: the social portrait of the student, which uses MOOCs, taking into account the psychological characteristics of the personality in the process of courses' designing, motivation for students' learning [5], factors for improving of students' performance, and so on.

Much attention is paid to the difficulties and barriers, faced by students in the process of electronic courses taking. Muilenburg \& Berge found eight factors, 
limiting student learning with MOOCs [12]. These include administrative sources, relationships, academic skills, technical skills, academic motivation, time and support of training, cost and access to the Internet, technical problems. The authors took into account the age of students, gender, ethnicity, type of educational organization, training skills, features of combining traditional classes and online courses. Shapiro and others analyzed the experience of students training with MOOCs, based on such indicators as students' motivation, their attitude to electronic educational resources, and barriers in the use of online courses [16].

Within the framework of this approach, a great interest of researchers is caused by the question of the influence of students' motivation on the effectiveness of open online courses taking, namely whether the mode of study influences the motivation of learning [1]. There are a series of studies, where motivation is considered as a relatively stable personal characteristic of a student, and as a paramount in determining the learning outcomes. An alternative point of view is based on the importance of the design of educational space, in the matter of increasing the motivation for learning. In the work of Hartnett, St. George \& Dron the application of selfdetermination theory in understanding the motivational aspects of students' learning with MOOCs, is discussed [4]. Hoskins \& Van Hooff in their study turned to an issue of socio-psychological portrait of students, who preferred to use online courses in the educational process. The authors identified the factors, affecting the students' achievements in training [6].

\section{Methods}

In our study, we used the method of questioning. The survey, consisting of 57 questions, was developed by a group of scientists of the Higher School of Economics, based on the data of the international consortium "Student Experience at a Research University" (SERU-I) [15]. The survey was conducted within the framework of the InterUniversity research project "Trajectories and experience of students of Russian universities", in particular as an International Comparative Study. Among the key topics, this questionnaire included the following aspects:

- The budget of students' time;

- Educational objectives of students;

- An assessment of educational environment;

-Involvement of students in training and participation in the best pedagogical practices;

- Interaction with teachers;

- Involvement of students in research activities at the university.

The study involved Russian universities, participating in the "5-100" program, and federal universities. Kazan Federal University was one of the participants in this study.
Since the questionnaire covers various aspects of the studentship, and interesting information on various issues, mentioned above, can be obtained, we focus our attention on the problem of interest to us: quite how do EER assist in training of students' of Kazan Federal University? To achieve this goal, we conducted a comparative analysis of the studied indicators among students of two groups. All the studied indicators were divided into the following categories:

- Social portrait;

- Educational activities;

- Professional competence;

- Satisfaction with the quality of education;

- Professional development.

778 students of Kazan (Volga region) Federal University took part in the study. This amount is $4.3 \%$ of the total number of students of KFU. This sample included students from all institutions and fields of education. The students were divided into two groups. The first group included 399 students with one or more experience in working with the electronic educational resources. The second group consisted of 379 students, who did not have any experience in working with EER.

\section{Results \\ Studying the Social Portrait of a Student}

Social profiling of student was based on 13 indicators, including the characteristics of the place of residence, financial position, academic performance, the number of hours, spent on different types of educational activities, leisure, volunteering. During the analysis of students' answers we found reliable differences in the following indicators.

In the group of students, who have already used EER (group 1), there was a higher level of performance $(\mathrm{p} \leq 0.01)$. Significant differences were revealed among students, getting high grades. As for the students with good and satisfactory performance, the shares of the tested persons were almost the same. Accordingly, it can be assumed, that initially more successful students, motivated to training activities and high results, along with other teaching aids, use EER in the learning process.

The main content of the student's social portrait was focused on the number of hours, spent on learning activities. It was revealed, that the students of the first group (group 1) spend more than 30 hours per week both on classroom activities $(p \leq 0,05)$ and on extracurricular activities $(p \leq 0,01)$. In the second group (group 2), it was observed, that students spent about $16-20$ hours per week $(\mathrm{p} \leq 0.05)$ mainly for lectures and seminars, while preparation for classes took no more than 5 hours per week ( $\mathrm{p} \leq 0.05$ ).

When analyzing the time, spent by students for sports, it can be noted, that in both groups, this figure is up to 10 hours a week. Sleep takes about 6-7 hours a day. The financial situation is generally satisfactory in both groups. 
Students, using electronic educational resources in their training, are more active in public life. Among them there are volunteers $(p \leq 0.01)$ and members of various student organizations $(\mathrm{p} \leq 0.01)$.

\section{The Study of Learning Activities}

Characteristics of student learning activities were compiled on the basis of 33 indicators, which can be generalized and grouped into 5 blocks. These include the characteristics of students' activities in the lessons, the specifics of preparing for classes, relationships and cooperation with teachers, with classmates, as well as the students' attitude to the performance of their training duties.

Analyzing the peculiarities of students' activities in the lessons, we found out, that in the first group there were distinctive features, determining the nature of their learning activities. These students significantly more often participate in discussions at seminars $(p \leq 0,05)$, make reports and presentations $(p \leq 0,01)$, use an average of $60-100 \%$ of compulsory literature in the academic year $(\mathrm{p} \leq 0,05)$.

Intellectual activity of students from compared groups at the lessons has its own peculiarities. When discussing the material, students of the first group more often use knowledge, concepts and ideas from different courses $(p \leq 0.01)$. They also often analyze the arguments and draw conclusions, based on them, generate new ideas, develop their own projects and concepts $(p \leq 0.01)$. Students, who use EER, more often defend their own point of view and confirm it with examples and facts $(\mathrm{p} \leq 0.05)$. Similar features of intellectual activity of students of both groups are as follows. Reproductive activities, consisting in analyzing of famous theories and methods, solving various tasks, are typical for students of both groups in equal measure. It is also worth noting, that the activity and initiative of students, when asking questions about the content of the course during lessons, is manifested at the average level in both groups.

Next, consider the specifics of students preparing for classes and additional types of knowledge. The quality of training of the first group students is significantly high. When doing homework, this category of students uses ideas and concepts from different academic disciplines $(\mathrm{p} \leq 0.01)$. We also found out, that they attend additional special research seminars $(\mathrm{p} \leq 0.05)$, and also they have experience in writing scientific articles $(\mathrm{p} \leq 0.01)$.

If we talk about the attitude of students towards their training duties, the students of the second group often miss classes without good reason and often come to classes unprepared.

Analyzing the relationships of students with teachers, we found out, that students with experience in working with electronic educational resources more often discuss ideas or concepts, related to the training course with teachers at extracurricular time (personally, by phone, by e-mail, at EER forums) ( $\mathrm{p} \leq$
0.01). Such students are involved by teachers in various scientific $(p \leq 0.01)$, creative and social projects $(p \leq 0.01)$. The importance of teacher's assessment and the level of requirements also affect the attitude of students towards their academic duties. Students of the first group make more efforts for studying the course $(\mathrm{p} \leq 0.05)$.

The mutual relations and cooperation of students with classmates in the process of learning activity differ in the compared groups. Students of the first group more often work on group projects and assignments during extracurricular time $(\mathrm{p} \leq 0.05)$.

\section{The Study of Professional Competences}

To estimate the level of development of professional competences, students were asked to assess how good are their skills in the following 12 professional competencies: analytical skills and critical thinking skills; the ability to express thoughts in writing, clearly and intelligibly; the ability to express thoughts orally, clearly and intelligibly; the ability to read and understand scientific literature; second language skills; student's understanding of the disciplinary field; knowledge of quantitative methods of analysis; leadership abilities; interpersonal skills; skills in working with library resources; presentation skills; the ability to understand art.

The results show, that with a high degree of certainty it can be said, that the students of the first group at a good level have the ability to express their thoughts orally, clearly and intelligibly $(\mathrm{p} \leq 0.05)$, to read and understand the scientific literature $(\mathrm{p} \leq 0.05)$. Such students are distinguished by the understanding of their disciplinary area $(\mathrm{p} \leq 0.05)$. Perhaps the experience with EER allowed students of the first group to demonstrate skills of working with library resources at a very good level, they know how to search for books, articles, and evaluate information sources $(\mathrm{p} \leq 0.05)$. In addition, with a high probability $(p \leq 0.05)$, it can be said, that students with experience in working with electronic educational resources have a good level of leadership skills $(\mathrm{p} \leq 0.05)$ and presentation skills $(\mathrm{p} \leq 0.01)$.

If we talk about students who do not have any experience in working with EER, the results of the study indicate, that they are able to express their thoughts clearly and intelligibly in writing $(p \leq 0.05)$, show sufficient level of communication skills $(\mathrm{p} \leq 0.05)$.

The students of these two groups are united by the fact, that they are equally familiar with the quantitative methods of analysis, have good second language skills, and are able to understand art. It can be assumed, that these competences are formed already in school years, when studying such subjects as foreign language, mathematics, history, literature, music. Perhaps, many of them could additionally engage in music and art schools, attend courses in the study of foreign languages. Thus, it can be argued 
that, regardless of whether students use electronic educational resources, during the training process or not, they have the same competences, listed above.

\section{The Study of Students' Satisfaction with the Quality of Education}

The characteristic of students' satisfaction with the quality of education was compiled on the basis of 19 indicators, which can be generalized and grouped into 3 blocks. These include satisfaction with the conditions in which the educational process is carried out at the university, the organization of leisure activities of students, as well as the quality of the work of teachers.

If we talk about the first aspect, the students of the first group highly appreciate the conditions, created at the university for self-tuition, the availability and accessibility of computer classes, classrooms for independent studies $(\mathrm{p} \leq 0.01)$, as well as informational support of studies at the university (informing about the schedule of classes, examinations and other organizational issues) $(\mathrm{p} \leq 0.01)$, availability of library resources $(\mathrm{p} \leq 0.01)$. In addition, students note the satisfaction from the variety of courses, available in the direction of student preparation $(\mathrm{p} \leq 0.01)$, the availability and variety of elective courses at the university $(\mathrm{p} \leq 0.01)$. The students of the second group are rather dissatisfied with the classroom conditions; they are not satisfied with the equipment, the seating capacity of classrooms $(\mathrm{p} \leq 0.01)$.

If you describe the leisure activities of students, it is highly probable, that the students of the first group are satisfied with the conditions, created at the university for sports $(p \leq 0.01)$, the organization of cultural leisure, the possibility of attending performances, concerts, creative evenings $(p \leq 0.01)$, receiving support for the implementation of student initiatives $(\mathrm{p} \leq 0.01)$.

In addition, we found a contradiction in the data: on the one hand, the students of the first group were satisfied with the conditions, created at the university, for obtaining the experience in research conducting or making creative products $(\mathrm{p} \leq 0.01)$. On the other hand, the students of the second group express their dissatisfaction, that they have not gained experience in conducting research or making creative products. We can assume, that since the students of the first group are in close contact with the teachers, they are motivated to study, they spend a lot of time for learning, this all contribute to the fact, that teachers invite such students to various projects and researches.

If we talk about how the students characterize the quality of work of university teachers, then the following trend is observed. The students of the first group are satisfied in various degrees with the quality of teaching of general education subjects $(p \leq 0.01)$, the quality of teaching of disciplines in the specialty of students $(p \leq 0.01)$, the quality of teachers' consultations on issues, related to training $(\mathrm{p} \leq 0.01)$, quality of work of young teachers $(\mathrm{p} \leq 0.01)$.

\section{Studying the plans of professional development of students}

Characteristics of plans for professional development of students consisted of the following indicators: the plans of students after graduation, the maximum level of education or the academic degree, which students planned to receive. It is highly probable, that the students of the second group plan to work with parttime employment $(p \leq 0.05)$ and to have their own business $(p \leq 0.05)$, and also to obtain a master's degree $(p \leq 0.05)$. Although we did not receive significant differences, it could be argued, that students from the first group were interested in obtaining a master's degree, and also wished to obtain a scientific degree in the future.

\section{Discussion}

Having studied the student's social portrait, we could conclude that the high educational motivation, the desire for self-actualization in various activities and high performance were the distinguishing features of the students of the first group. Perhaps, this can also explain the use of EER in educational activity as one of the variants of teaching aid.

This feature of the students from the first group determines the students' learning characteristics, which consist in cooperation with teachers and classmates at extra-curricular time, in a higher quality of preparation for classes, and participation in additional specialized scientific seminars. It should be noted, that intellectual activity of students is characterized by creative approach and generation of new ideas, a systematic approach to the use of interdisciplinary knowledge. Their educational activity is characterized not only by the actualization of their knowledge, but also by the production of new knowledge in the research and development format.

The experience of students in working with electronic educational resources, in our opinion, contributes to the development of skills in working with library resources. They know how to search for books, articles, and to evaluate information sources. In addition, there is a tendency, that high motivation, high academic achievements, attendance of additional courses contribute to the fact, that these students have such competencies as "understanding their disciplinary area", "presentation skills". At the same time, it is necessary to study in more detail, why these students have a better ability to express their thoughts orally, clearly and intelligibly; their leadership abilities; and why the students of the second group have the ability to express their thoughts clearly and intelligibly in writing, the ability to communicate with people. 


\section{Conclusion}

Summing up our research, we can make the following conclusions. Initially, more successful students, motivated for learning activities and high results, along with other teaching aids, use EER in the learning process. Students, who have experience in working with electronic educational resources are most often satisfied with the learning environment, they do well in studies, take part in public life of the university. At the lessons they show their leadership qualities, they are able to defend their point of view, have the skills to work with literary sources. Intellectual activity of students of the first group is distinguished by creative approach and generation of new ideas, a systematic approach to the use of interdisciplinary knowledge. An interesting fact was also revealed, which is difficult to explain in the framework of this study, and requires further study. Students, having experience in working with electronic educational resources, mainly live in a dorm, and the most students, who do not use EER in educational activities, live with parents.

The fact, that the students of the first group are satisfied with the conditions of study during academic and extra-curricular time, for sports and leisure, is also interesting for further study. They are also satisfied with the quality of teaching at the university; they are satisfied with the quality of teaching disciplines in the specialty, consultations. While the students of the second group are not satisfied with the conditions, in which classes are held.

\section{Acknowledgements}

The work is performed according to the Russian Government Program of Competitive Growth of Kazan Federal University.

\section{References}

1. Bekele, T.A. (2010). Motivation and satisfaction in internet-supported learning environments: A review. Educational Technology and Society, 13(2), 116-127.

2. Bernard, R.M., Abrami, P.C., Lou, Y., Borokhovski, E., Wade, A., Wozney, L., Huang, B. (2004). How does distance education compare with classroom instruction? A meta-analysis of the empirical literature. Review of Educational Research, 74(3), 379-439.

3. Gikandi, J.W., Morrow, D., \& Davis, N.E. (2011). Online formative assessment in higher education: A review of the literature. Computers and Education, 57(4), 2333-2351. doi:10.1016/j.compedu.2011.06.004.

4. Hartnett, M., St. George, A., \&Dron, J. (2011). Examining motivation in online distance learning environments: Complex, multifaceted, and situationdependent. International Review of Research in Open and Distance Learning, 12(6), 20-38.
5. Hew, K.F., \& Cheung, W.S. (2014). Students' and instructors' use of massive open online courses (MOOCs): Motivations and challenges. Educational Research Review, 12, 45-58. doi:10.1016/j.edurev.2014.05.001.

6. Hoskins, S.L., \& Van Hooff, J.C. (2005). Motivation and ability: Which students use online learning and what influence does it have on their achievement? British Journal of Educational Technology, 36(2), 177-192. doi:10.1111/j.14678535.2005.00451.x.

7. Lee, Y., \& Choi, J. (2011). A review of online course dropout research: Implications for practice and future research. Educational Technology Research and Development, 59(5), 593-618. doi:10.1007/s11423-010-9177-y.

8. Liyanagunawardena, T.R., Adams, A.A., \& Williams, S.A. (2013). MOOCs: A systematic study of the published literature 2008-2012. International Review of Research in Open and Distance Learning, 14(3), 202-227.

9. Longstaff, E. (2017). How MOOCs can empower learners: A comparison of provider goals and user experiences. Journal of further and Higher Education, 41(3),

314-327. doi:10.1080/0309877X.2015.1100715.

10. Marshall, S. (2014). Exploring the ethical implications of MOOCs. Distance Education, 35(2), 250-262. doi:10.1080/01587919.2014.917706.

11. Martin, F.G. (2012). Education: will massive open online courses change how we teach. Communications of the ACM, 55(8), 26-28. doi:10.1145/2240236.2240246.

12. Muilenburg, L.Y., \& Berge, Z.L. (2005). Students' barriers to online learning: A factor analytic study. Distance Education, 26(1), 29-48. doi:10.1080/01587910500081269.

13. Nunez, J.L.M., Caro, E.T., \& Gonzalez, J.R.H. (2017). From higher education to open education: Challenges in the transformation of an online traditional course. IEEE Transactions on Education, 60(2), 134-142. doi:10.1109/TE.2016.2607693.

14. Phan, T., McNeil, S.G., \& Robin, B.R. (2016). Students' patterns of engagement and course performance in a massive open online course.Computers and Education, 95, 36-44. doi:10.1016/j.compedu.2015.11.015.

15. The research project "Trajectories and experience of students of Russian universities" participating in the program " $5: 100 " / /$ https://ioe.hse.ru/collaborative_project/stuff.

16. Shapiro, H.B., Lee, C.H., Wyman Roth, N.E., Li, K., Çetinkaya-Rundel, M., \&Canelas, D.A. (2017). Understanding the massive open online course (MOOC) student experience: An examination of attitudes, motivations, and barriers. Computers and Education, 110 , 35-50. doi:10.1016/j.compedu.2017.03.003.

17. Toven-Lindsey, B., Rhoads, R.A., \& Lozano, J.B. (2015). Virtually unlimited classrooms: Pedagogical 
practices in massive open online courses. Internet and
Higher
Education,
24 ,
1-12.

doi:10.1016/j.iheduc.2014.07.001.

18. Vivian, R., Falkner, K., \& Falkner, N. (2014).

Addressing the challenges of a new digital technologies curriculum: MOOCs as a scalable solution for teacher professional development. Research in Learning Technology, 22. doi:10.3402/rlt.v22.24691. 